\title{
Negatif basınçlı yara tedavisi ve ortopedi pratiğinde kullanımı
}

\author{
Negative pressure wound therapy and orthopedic clinical usage
}

\author{
Nadir Özkayın¹, Mehmet Erdem², Yiğit Özer Tiftikcioğlu²
}

${ }^{1}$ Ege Üniversitesi Tıp Fakültesi, Ortopedi ve Travmatoloji Kliniği, İzmir

${ }^{2}$ Ege Üniversitesi Tıp Fakültesi, Plastik, Rekonstrüktif ve Estetik Cerrahi Kliniği, İzmir

\begin{abstract}
Negatif Basınçlı Yara Tedavisi (NBYT) son yıllarda ortopedik travmalarda popülaritesi artan bir yara bakım yöntemidir. Modern NBYT sistemleri; porlu sünger sistemi, baskılı pansuman sistemi ve negatif basınçüreten vakum pompası içermektedir. Açık kırıklarda, kronik yaralarda, kontamine yaralarda cerrahi debridman sonrası ek tedavi yöntemi olarak kullanılmaktadır. Bu derleme, NBYT'nin ortopedik cerrrahiler ile ortopedik yaralarda klinik kullanımının ve vakum tedavisinin temel endikasyonlarına dikkat çekmeyi amaçlamıştır.
\end{abstract}

Anahtar sözcülkler: negatif basınçlı yara tedavisi; VAC; yara bakımı
Negative Pressure Wound Therapy (NPWT) is an increasingly popular wound care procedure for orthopedic traumas in recent years. Modern NPWT systems including pored sponge systems, pressured dressing systems, and vacuum pumps producing negative pressure are used in compound fractures, after surgical debridement in contaminated wounds as an additional therapy. In this review, it is aimed to point out the basic indications of NPWT clinical usage in orthopedic surgeries and wounds, and vacuum therapy.

Key words: negatif pressure wound therapy; VAC; wound care
BYT (Negatif Basınçlı Yara Tedavisi) ilk olarak 1989 yılında Charker ve arkadaşları ${ }^{[1]}$ tarafından "insizyonel ve kutanöz fistüllerde drenaj sistemi” tanımlaması ile kullanılmaya başlanmıştır. 1993 yılında Fleischmann ve arkadaşları ${ }^{[2]}$ bu sisteme benzer bir sistem keşfedip, negatif basınç üreten poliüretan sünger kullanarak, bunun açık kırıklarda granülasyon dokusu gelişmesine pozitif etkisi olduğunu gözlemlemişlerdir.

NBYT, geleneksel yara tedavisine alternatif olarak sıklıkla kullanılmaktadır. Çoğu klinisyene göre, NBYT yara erken kapanmasında ve enfeksiyon azaltılmasında geleneksel yara bakım yöntemlerine göre daha etkili bir yöntemdir. Artan bu popülaritesine rağmen yara tedavisinde 'maliyet etkin' olarak kullanılması önerilmektedir. Bu derleme yazı, NBYT endikasyonları, kontrendikasyonları ve ortopedik cerrahide kullanım alanlarını belirtmek amacıyla yazılmıştır.

\section{NBYT CIHAZLARI}

Bütün NBYT sistemleri; porlu sünger, oklüzif yarı geçirgen yara kapatma materyali ve negatif basınç yaratan emici bir hortumla yaraya bağlanan bir cihazdan oluşmaktadır (Şekil 1).

Çok farklı çeşitlerde çalışan, farklı süngerleri sahip, farklı kalitede, yıkamalı veya yıkamasız olan çeşitli vakum cihazları mevcuttur. Tablo 1 , şu an ticari olarak kullanılan sistemler ve bunların farklılık ve benzerliklerini göstermektedir.

\section{ETKI MEKANIZMASI}

Morykwas ve arkadaşları ${ }^{[4]}$ yapmış oldukları hayvan modeli çalışmasında, $125 \mathrm{mmHg}$ negatif basınç uygulandığında granülasyon dokusunun maksimum olarak geliştiğini gözlemlemişlerdir. Bu etkinin, negatif basınç $5 \mathrm{dk}$ uygulanıp $2 \mathrm{dk}$ ara verildiği zaman daha da arttığı

- Illetişim adresi: Prof. Dr. Nadir Özkayın, Ege Üniversitesi Ortopedi ve Travmatoloji Kliniği, Bornova, İzmir Tel: 0532 - 3674022 e-posta: nadirozkayin@gmail.com

- Geliș tarihi: 20 Mart 2017 Kabul tarihi: 20 Mart 2017 

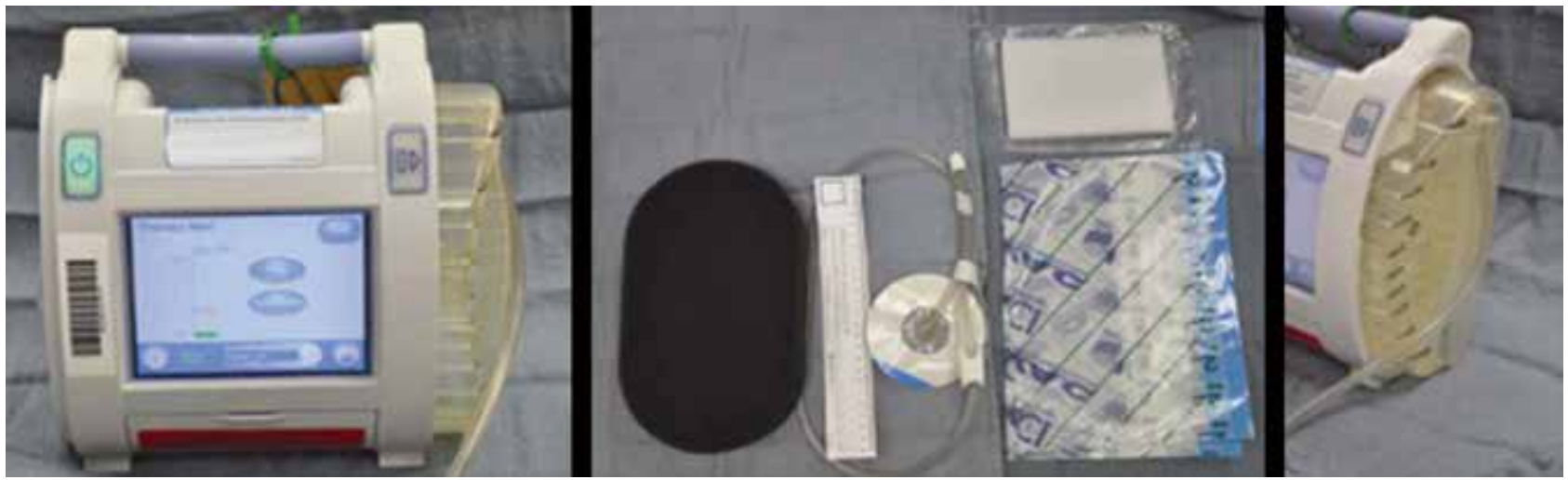

Şekil 1. VAC cihazı, süngeri ve toplama kabı. ${ }^{[3]}$

görülmüştür. "Aralıklı negatif basınç" uygulanmasında, kan akımının da arttığı gözlemlenmiş, sürekli basınç uygulaması sonrası \%63, aralıklı basınç uygulaması sonrasında \%103 oranında granülasyon dokusu artışı görülmüştür. Akut travmatik yaraların takibinde “125 mm Hg basınç" önerilmektedir. ${ }^{[5-7]}$

Orgill ve arkadaşları ${ }^{[8]}$ NBYT'nin yara iyileşmesinde etkilerini dörde ayırmışlardır;

1- Makro-deformasyon: yara kenarlarına çekim kuvveti ile yarada kontraksiyona neden olma.

2- Yara çevresinde stabilizasyon: yarayı dış mikroorganizmalardan koruma, yarayı ılık ve nemli tutma.

3- Yumuşak dokuda eksüdaları alarak, yarada ödemi azaltma.

4- Mikro-deformasyon: yara yüzeyinde hücresel proliferasyona neden olma.

\section{KONTRENDIKKASYONLARI}

NPYT genellikle etkili ve güvenli bir tedavi olarak düşünülür. Ancak, bazı durumlarda kullanılması önerilmemektedir ve kontrendikedir. ${ }^{[9]}$

Açıkta bulunan yapıların varlığında; NPYT süngeri açıkta bulunan damar, sinir, organ, anastomoz alanlarına temas etmemelidir.

\section{Enfeksiyon}

Enfeksiyon (osteomiyelit de dahil) gözlenen yaralarda, uygulamadan önce debridman yapılmalıdır.

\section{Kanama}

Kanamalı alanlara uygulanmamalıdır. Uygulama sırasında kanama gelişirse negatif basınç durdurulmalı, sünger çıkarılıp baskılı pansumana geçilmelidir.

Tablo 1. Türkiye'de bulunan vakum cihazları

\begin{tabular}{|c|c|}
\hline $\mathrm{VAC}^{\circledR}$ & $\begin{array}{l}\text { - Yıkamalıdır. Yara yerine instilasyon ile lokal antibiyoterapi ve asepsi yapılabilir. } \\
\text { - Diğer vakum cihazlarına göre pahalıdır. Ancak etkinliği ve yarada yarattığı çabuk iyileşme } \\
\text { 'maliyet etkin' olarak kullanılabilir. }\end{array}$ \\
\hline SMITH\&NEPHEW ${ }^{\circledR}$ (tıkanmayan portlu) & $\begin{array}{l}\text { - Yıkamalı değildir. Portunda tıkanma olmaması önemli özelliğindendir. Uyarı sistemleri } \\
\text { mevcuttur. 'Maliyet etkin' olarak kullanılmalıdır. }\end{array}$ \\
\hline TRU-VAC ${ }^{\circledR}$ & - Yıkamalı değildir. İlk ikisine göre fiyatı uygundur. Uygun endikasyonlarda önerilir. \\
\hline TOPIVAC ${ }^{\circledR}$ & - Yıkamalı değildir. İlk ikisine göre fiyatı uygundur. Uygun endikasyonlarda önerilir. \\
\hline ONFORT ${ }^{\circledR}$ & Ialı değildir. İlk ikisine göre fiyatı uygundur. Uygun endikasyonlarda önerilir. \\
\hline
\end{tabular}

Klinik pratiğimizde en çok ilk iki cihazı kullanmaktayız. Yara takibinde en fazla bu iki cihazın yararlı olduğu ve hızlı iyileşmenin en fazla bu iki cihazda olduğunu

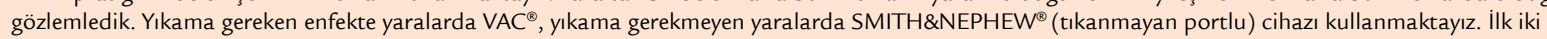
cihazın diğerlerine göre daha pahalı olduğu ve 'maliyet etkin' olarak kullanılması gerektiğini düşünmekteyiz. Diğer üç cihazı, enfekte olmayan, gecikmiş kapanma yapılacak ve uzun süreli vakum tedavisi kullanılmayacak, yakın zamanda operasyonla kapanan yaralarda kullanmaktayız. 


\section{Malignite}

Tümör olan alanlara uygulanmamalıdır. Tümöral dokuda büyüme etkisi yapmakta, aynı zamanda tümöral doku kanamaya yatkın olduğu için, uygulama kanamayı arttırmaktadır.

\section{Alerji}

Gümüş veya uygulanan süngere alerji varsa yapılmamalıdır.

\section{Diğer}

İskemik yaralara, debridman gerektiren nekrotik dokular varsa debride edilmeden önce, frajil deriye, fistül üzerine uygulanmamalıdır.

Negatif basınçlı yara tedavisi gerektirmeyen yaralarda ve en az iki sünger değişimi veya bir haftalık tedavi sonrasında yarada değişim olmaması gibi durumlarda kullanımı "kötü endikasyon" olarak değerlendirilir ve tedavinin durdurulması gerekir. ${ }^{[10]}$

NBYT endikasyonları ${ }^{[11]}$;

- Akut ve kronik yaralar

- Subakut yaralar (insizyon dehissansı)

- Kronik, diyabetik ve bası yaraları

- Meşlenmiş greft uygulama öncesi ve sonrası

- Flep operasyonlarından sonra

NBYT kontrendikasyonlari[ ${ }^{[11]}$;

- Organ veya vücut kavitelerine fistül

- Yarada debride edilmemiş nekrotik doku bulunması

- Eskar dokusu üzerine uygulama

- Tedavi edilmemiş osteomiyelit

- Antikolagülan alımı

- Hemostaz gereken yaraya uygulama

Ekpoze organ veya kan damarı bulunan yaraya uygulanması, kısmi kontrendikasyondur. ${ }^{[11]}$

\section{NASIL KULLANILMALIDIR}

NBYT her 24 saatlik sürede 22 saat uygulanmalıdır. Batarya bitimi ve kaçak uyarısı, efektif olmayan çekim iki saatten fazla olduğu zaman cihaz çıkarılmalıdır. Cihazın süngeri 48-72 saatlik aralarla haftada üç kez değiştirilmelidir. Enfekte yaralar daha sık sünger değişimi gerektirir. ${ }^{[10]}$

Toplama kabı, dolarsa veya tedavi başlangıcı sonrası haftada bir kez değiştirilmesi gerekir. Yaralanma, ağrı ve yapışma gibi durumlardan kaçınmak için cihaz,

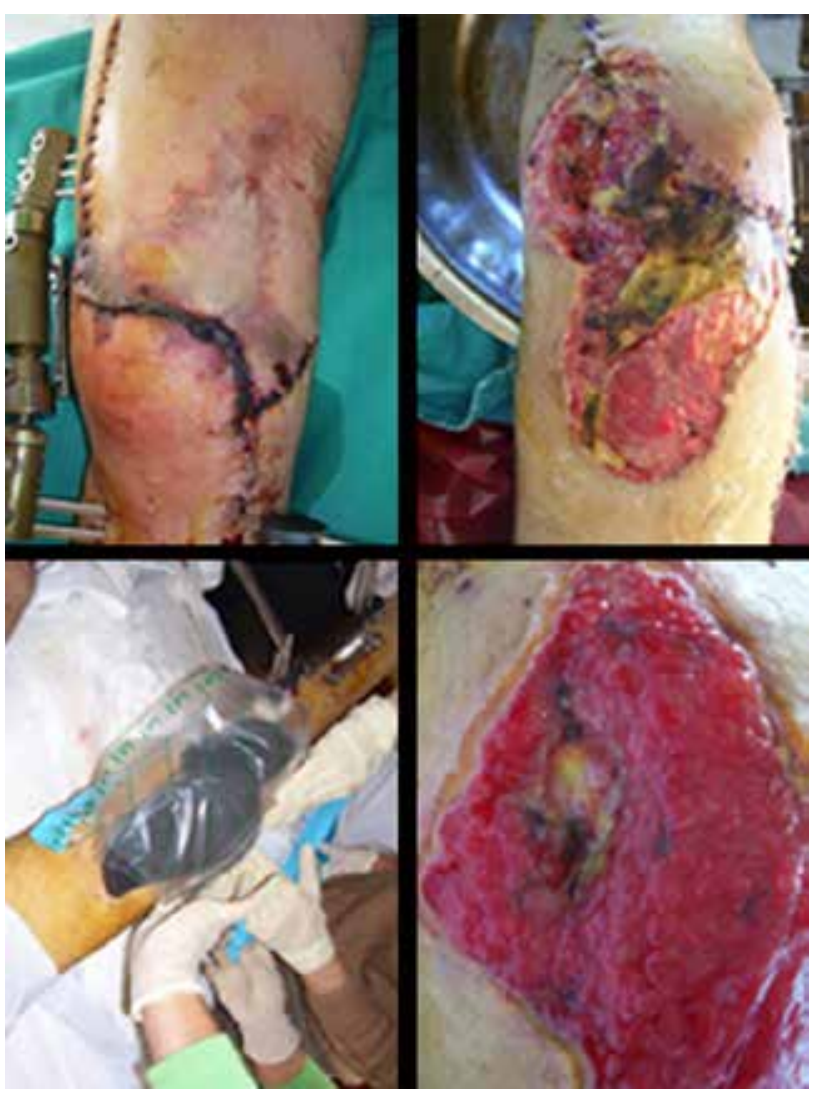

Şekil 2. Postnekroz VAC tedavisi ve 7. günde granülasyon dokusu gelişimi.

sünger çıkarılmadan $30 \mathrm{dk}$ önce kapatılmalıdır. Serum fizyolojik ile sünger iyice yıkanıp, gerekirse xylocaine ile lokal analjezi sağlanarak çıkarılması gerekir. ${ }^{[10]}$

\section{ORTOPEDi KLINIĞiNDE KULLANIM ALANLARI}

Açık kemik kırıkları, ortopedi pratiğinde yaygın bir problemdir (Şekil 2); yüksek oranda derin dokularda enfeksiyon ve osteomiyelit ile ilişkilidir. Çoğu araştırmada, enfeksiyon oranı \%16-66 arasında değişmektedir. Açık tibia kırıklarında, büyük, iyileşmesi zayıf ve geç olan yaralar oluşur. Virani SR ve arkadaşları ${ }^{[12]}$ açık tibia kırıklarında uygulanan negatif basınçlı yara tedavisinin yara yeri enfeksiyonu ve osteomiyelit ile ilgili etkisini, ilk ileriye dönük çalışma olarak yapmışlardır. Bunun sonucunda etki, akut ve derin enfeksiyonlu veya osteomiyelitin negatif basınçlı tedavi grubunda $\% 4,6$, kontrol grubunda \%22 olarak saptanmıştır. Bakteriyel kolonizasyonun da, \%6,9 ve \%34 olarak gruplar arası farklılığı gözlemlenmiştir. ${ }^{[12]}$

Yarada bakteriyel kolonizasyon, yara iyileşmesi ve yara enfeksiyonunda en önemli faktörlerden biridir. 


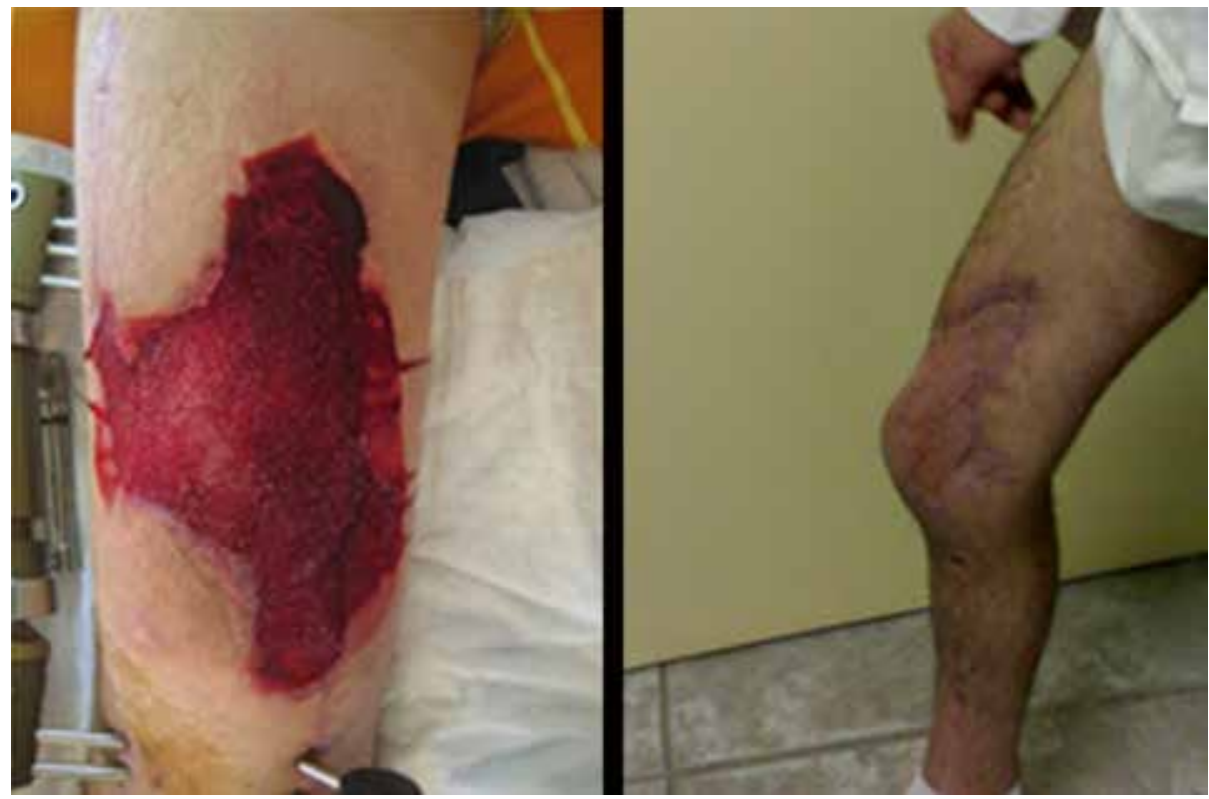

Şekil 3. Vakum tedavisinin 14. günü, kemiğin granülasyon dokusu ile kaplanması.

NBYT'nin yara çevresinde bakterileri temizlemesi, sıklıkla gözlenen yararlarından biridir. Bazı çalışmalarda, NPYT kullanımıyla yarada S.aureus ve S.Epidermidis miktarında azalma gözlenmesine rağmen ${ }^{[4]}$, bazı çalışmalarda farklııık gözlenmemiştir. ${ }^{[13]}$

Cerrahi debridman ve NBYT birlikte olan, Jentzch T ve arkadaşları yaptıkları çalışmada, hastalarda kombine rejimle, debridman, irrigasyon, NBYT ve antibiyotik tedavisi ile, gram pozitif bakterilerden olan, fakültatif anaerobik bakteriler, S.aureus, koagülaz-negatif stafilokoklar (KNS) ve psödomonas gibi bakterilerde, bakteri yükünde azalma olduğu gözlemlenmiştir. Yüksek oranda yara kapaması, düşük revizyon oranları ile kısa sürede başarılmıştır. ${ }^{[14]}$

Dehisens ve hematom riski yüksek olan cerrahi insizyonlar ve kapalı yaralarda, destekleyici tedavi olarak NBYT kullanımı önerilmektedir. Meeker ve arkadaşlarının domuz yara modelinde yaptığı çalışmaya göre, NBYT olan ve olmayan yaralar karşılaştırıldığında, üç gün sonra yara gerilim gücünün NBYT kullanılan yaralarda daha belirgin olduğu gözlenmiştir. ${ }^{[15]}$ Stannart ve arkadaşları, NBYT'nin yüksek enerjili travmalar sonrası cerrahi insizyonlarda oluşan hematoma etkisi araştırmışlardır. Kırk dört hasta, cerrahi sonrası hematom drene edilip, NBYT ve kompresyon bandajı ile takip edilip sonuçları karşılaştırılmış, NBYT'nin hızlıca iyileştirme ve daha en enfeksiyon oranına sahip olduğu gözlenmiştir (1,6 güne karşı 3,1 gün, \%8'e karşı \%16 enfeksiyon oranları). ${ }^{[16]}$
Ortopedi kliniğinde NBYT'nin en erken kullanım alanı travma hastalarıdır (Şekil 3). Sağlıklı ve kanama gözlenen dokulara kadar debridman, travmatik yaraların tedavisinde temel prensiptir. Gomol ve arkadaşları NBYT tedavisinin çeşitli ortopedik yaralarda kullanıldığı 35 hastalık bir seri yayımlamışlardır. Hastalar; ayak travması, diz travması, kalça revizyon cerrahisi ve tibia kırıkları gibi cerrahi yaralardan ameliyat olan kişiler içinden seçilmiştir. Bu aynı zamanda, hastaların cerrahi sonrası yara drenajı gerektiren yüksek riskli olduğu gruptur. NBYT, ortalama olarak üç gün kullanılmıştır. Pansuman değişimi daha sorunsuz olmuş ve yara bakım süresi belirgin ölçüde kısalmıştır. Yüksek risk olarak ayrılan grupta herhangi bir enfeksiyon gözlenmemiştir. ${ }^{[17]}$

\section{TARTIŞMA}

NBYT ile granülasyon dokusunda artma ve iyileşmede hızlanma, iki mekanizma ile açıklanmaktadır. Kontrollü vakum uygulanması sonrasında, yarada bulunun interstisyel sıvı artan basınç ile emilmektedir. Bunun sonucunda, interstisyel basınçta düşme meydana gelmektedir. İnterstisyel basınç düştüğü zaman, kapillerlerde kapalı bulunan damar kapakçıkları açımakta ve yara çevresinde kan akımı artmaktadır. Aynı mekanizma, vakum tedavisi sonrası ekstremitede kompartman sendromu ve abdominal kompartman sendromunda basınçların azalmasından da sorumludur. Dokuda biriken potansiyel olarak zararlı maddelerin 
vakumla emilimi de, yara iyileşmesini hızlandırmada ikincil mekanizmadır. Crush yaralanması sonrası, dokuda biriken miyoglobin sistemik dolaşıma katılarak akut renal yetmezliğe neden olabilir. Negatif basınçlı yara tedavisi ile, miyoglobin seviyelerinin crush yaralanma yerinde düştüğü, yapılan çalışmalarda gösterilmiştir. Ek olarak, domuzlarda doxorubicin ekstravazasyon yaralarının ve böcek ısırıkları sonrasında dokuya salınan toksik maddelerin NBYT ile başarılı olarak tedavi edildiği gözlenmiştir. ${ }^{[18]}$

Plastik cerrahi pratiğinde sık uygulanan işlemler olan doku genişletme ve osteojenik distraksiyonda gözlenen mekanik etkilerle dokuda gerginliğe uğrayan hücrelerde artmış mitotik çoğalma gözlenir. NBYT de bu işlemlerdeki mekanik etkilerin yapmış olduğu hücre çoğalmasına benzer etkiler göstermektedir. Mekanik etkilerin artması sonrasında, hücrelerde moleküler değişiklik oluşur. Hücrede; iyon konsantrasyonları, membran iyon kanalları geçirgenliği, sekonder mesaj proteinleri üretimi, moleküler yolakların aktivasyonu ve gen ekspresyonu artışı gelişiri. ${ }^{[19]}$

\section{SONUÇ}

NBYT, ortopedik travmalarda alternatif bir yara tedavi yöntemidir. Bu yöntemin yararları, daha az sıklıkta pansuman değişimi ve ağrıda azalmadır. Kesin olarak insizyonlarda komplikasyon ve enfeksiyon sıklığında azalmayı gösteren, ek olarak büyük bir çalışma yapılmamıştır. NBYT'nin, konvansiyonel yara bakım tedavilere göre belirgin bir başarı oranı bulunmaktadır. NBYT'nin ortopedik klinik endikasyonlarının daha kesin ortaya konulması için, konvansiyonel yara bakım tedavilerine ek olarak, maliyet araştırması ve adjuvan terapileri de içine alan büyük bir yara bakım çalışması gerekir.

NBYT'nin avantajlarl ${ }^{[10]}$;

- yara eksudası emilimi,

- yarada hızlı granülasyon dokusu gelişimi,

- endike hastalarda konvasiyonel yara bakım tedavisine göre daha etkin bir yöntem olması,

- interstisyel doku sıvısı emilimi sağlayarak yara iyileşmesini hızlandırması ve

- sık pansuman değişimini ortadan kaldırmasıdır.

NBYT'nin dezavantajları ${ }^{[10]}$;

- nekrotik ve enfekte yarada debridmanın yerini tutmaması,

- fiksasyon için kullanılan plakların üzerine granülasyon dokusu geliştirmemesi,
- periferik arter hastalıklarına bağlı gelişen yaralarda kullanılmaması,

- pansuman değişimlerinin ağrılı olabilmesi,

- iki pansuman değişimi veya bir hafta sonra yarada değişim yoksa kullanılmaması,

- pahalı bir tedavi yöntemi olması ve konvansiyonel yara bakım tedavisi ile birlikte 'maliyet etkin' olarak kullanılmasının gerekmesidir.

\section{KAYNAKLAR}

1. Chariker ME, Jeter KF, Tintle TE, Bottsford JE. Effective management of incisional and cutaneous fistulae with closed suction wound drainage. Contemp Surg 1989;34:59-63.

2. Fleischmann W, Strecker W, Bombelli M, Kinzl L, Vacuum sealing as treatment of soft tissue damage in open fractures. Der Unfallchirurg 1993;96(9):488-92.

3. Streubel PN, Stinner DJ, Obremskey WT, Use of negativepressure wound therapy in orthopaedic trauma. J Am Acad Orthop Surg 2012;20(9):564-74. Crossref

4. Morykwas MJ, Argenta LC, Shelton-Brown El, McGuirt W. Vacuum-assisted closure: a new method for wound control and treatment: animal studies and basic foundation. Ann Plast Surg 1997;38(6):553-62.

5. Steiert AE, Gohritz A, Schreiber TC, Krettek C, Vogt PM. Delayed flap coverage of open extremity fractures after previous vacuum-assisted closure (VAC) therapy -worse or worth? J Plast Reconstr Aesthet Surg 2009;62(5):675-83. Crossref

6. Leininger BE, Rasmussen TE, Smith DL, Jenkins DH, Coppola C. Experience with wound VAC and delayed primary closure of contaminated soft tissue injuries in Iraq. J Trauma 2006;61(5):1207-11. Crossref

7. Fang R, Dorlac WC, Flaherty SF, Tuman C, Cain SM, Popey TL, Villard DR, Aydelotte JD, Dunne JR, Anderson AM, Powell ET 4th. Feasibility of negative pressure wound therapy during intercontinental aeromedical evacuation of combat casualties. J Trauma 2010;69 Suppl 1:S140-5. Crossref

8. Scherer SS, Pietramaggiori G, Mathew JC, Prsa MJ, Huang S, Orgill DP. The mechanisms of action of the vacuum-assisted closure device. Plast Reconstr Surg 2008;122(3):786-97. Crossref

9. V.A.C ${ }^{\circledR}$ Therapy Clinical Guidelines. A Reference Source For Clinicians; 2005. Available at: http://research.vuse. vanderbilt.edu/srdesign/2005/group27/KCI\%20operating\%20 procedures.pdf

10. Robert $\mathrm{N}$. Negative pressure wound therapy in orthopaedic surgery. Orthop Traumatol Surg Res 2017;103(1S):S99-103. Crossref

11. Banwell P, editor. The VAC Therapy Clinical Guidelines: A reference source for clinicians. UK: Kinetic Concepts, Inc.; 2005. Available at: http://www.icid.salisbury.nhs.uk/ ClinicalManagement/TissueViability/Documents/889dd571 1 f874484b9ffaac2ee29745bKCIEnglishNov05online.pdf

12. Virani SR, Dahapute AA, Bava SS, Muni SR. Impact of negative pressure wound therapy on open diaphyseal tibial fractures: A prospective randomized trial. J Clin Orthop Trauma 2016;7(4):256-9. Crossref

13. Weed T, Ratliff C, Drake DB. Quantifying bacterial bioburden during negative pressure wound therapy: does the wound VAC enhance bacterial clearance? Ann Plast Surg 2004;52(3):276-80. 
14. Jentzsch T, Osterhoff G, Zwolak P, Seifert B, Neuhaus V, Simmen $\mathrm{H}$, Jukema GN. Bacterial reduction and shift with NPWT after surgical debridements: a retrospective cohort study. Arch Orthop Trauma Surg 2017;137(1):55-62. Crossref

15. Meeker J, Weinhold P, Dahners L. Negative pressure therapy on primarily closed wounds improves wound healing parameters at 3 days in a porcine model. J Orthop Trauma 2011;25(12):756-61. Crossref

16. Stannard JP, Robinson JT, Anderson ER, McGwin G Jr, Volgas DA, Alonso JE. Negative pressure wound therapy to treat hematomas and surgical incisions following high-energy trauma. J Trauma 2006;60(6):1301-6. Crossref
17. Gomoll AH, Lin A, Harris MB. Incisional vacuum-assisted closure therapy. J Orthop Trauma 2006;20(10):705-9. Crossref

18. Morykwas MJ, Simpson J, Punger K, Argenta A, Kremers L, Argenta J. Vacuum-assisted closure: state of basic research and physiologic foundation. Plast Reconstr Surg 2006;117(7 Suppl):121S-6S. Crossref

19. Silver F, Siperko LM. Mechanosensing and mechanochemical transduction: how is mechanical energy sensed and converted into chemical energy in an extracellular matrix? Crit Res Biomed Eng 2003;31(4):255-331. 